\title{
Effects of body size, water current and microhabitat on mucous-thread drifting in post-metamorphic gastropods Lacuna spp.
}

\author{
André Martel ${ }^{1}$, Thomas Diefenbach ${ }^{2}$ \\ ${ }^{1}$ Research Division, Canadian Museum of Nature, PO Box 3443, Station D, Ottawa, Ontario, Canada K1P 6P4 \\ ${ }^{2}$ Department of Zoology, University of Alberta, Edmonton, Alberta, Canada T6G 2E9
}

\begin{abstract}
The behaviour of snails was studied using a miniature flow tank mounted on a stereomicroscope equipped with a video camera. For Lacuna vincta, juveniles (ca $\leq 3 \mathrm{~mm}$ shell length) displayed foot-raising behaviour and initiated drifting in less time than adults ( $\mathrm{ca} \geq 3.5$ to $4 \mathrm{~mm}$ ). In contrast, there was no difference in juvenile and adult responses in $L$. variegata. When exposed to water current, individuals of both species usually displayed foot-raising behaviour, which was usually followed by mucous-thread drifting. Both oscillatory ( 8 to $9 \mathrm{~s} \mathrm{cycle}^{-1}$ ) and unidirectional water currents triggered foot-raising and drifting (peak water velocity: 15 to $17 \mathrm{~cm} \mathrm{~s}^{-1}$ ). Compared with individuals maintained in favourable microhabitats (dishes containing some of the algae from which they were originally collected in the field), the likelihood of foot-raising and drifting was 3 to 5 times higher in juveniles maintained in unfavourable microhabitats before the experiment $(24 \mathrm{~h}$ in dishes containing no algae on which to crawl and feed). In the field, unfavourable microhabitats, those lacking proper algal substrate or shelter, may increase the likelihood of post-metamorphic dispersal by triggering mucous-thread drifting by water current
\end{abstract}

\section{INTRODUCTION}

Dispersal of post-metamorphic stages drifting in the water column is part of the life history of many molluscs. It is common in bivalves with a planktonic larval stage (marine: Bayne 1964, Sigurdsson et al. 1976, Beukema \& Vlas 1989; brackish/fresh water: Prezant \& Chalermwat 1984, Martel 1993), as well as in several brooding taxa (Martel \& Chia 1991a). Post-metamorphic drifting occurs in several marine gastropods, including Helcion, Barleeia, Tricolia and Lacuna (Vahl 1983, Johnson \& Mann 1986, Martel \& Chia 1991a, b). Post-metamorphic Lacuna spp. were, after Mytilus spp., the most abundant drifters collected in off-bottom collectors deployed in a rocky intertidal area in Barkley Sound, Vancouver Island, Canada (Martel \& Chia 1991a). In many species it is accomplished by means of long mucous threads secreted by the foot and which act like a sail by increasing the hydrodynamic drag, enabling transport by water current (Sigurdsson et al. 1976, Lane et al. 1982, 1985, Vahl 1983, Martel \& Chia 1991b)
Martel \& Chia (1991b) demonstrated the occurrence of active participation during the initial phase of postmetamorphic drifting in 2 species of Lacuna and showed that in these molluscs, drifting is not always just a consequence of accidental dislodgement. They described a behaviour that precedes drifting, called 'foot-raising'. The snail quickly raises its metapodium high above the substrate, causing mucus produced and accumulated under the foot to be carried by vortices downstream from the shell and stretched by water current. A long, extensible drifting thread, up to 160 times the length of the shell is produced, which enables the snail to drift in an almost neutrally buoyant fashion (Martel \& Chia 1991b).

Although mucous-drifting in post-metamorphic molluscs when exposed to water current is known (e.g. Vahl 1983, Prezant \& Chalermwat 1984), empirical studies focusing on factors controlling the triggering of post-metamorphic drifting are scarce. Sorlin (1988) studied the effect of water current and temperature on floating behaviour in the small tellinid bivalve 
Macoma balthica. Similar studies have not been published on gastropods. Information on factors controlling post-metamorphic drifting in molluscs can provide insight into the adaptive significance of this widespread behaviour with respect to its role in recruitment processes, population dynamics and dispersal in general. The present investigation focuses on the role of 3 factors in controlling the initiation of foot-raising and post-metamorphic mucous-thread drifting in 2 species of Lacuna.

\section{MATERIALS AND METHODS}

This study was conducted on Vancouver Island, British Columbia, Canada $\left(48^{\circ} 50^{\prime} \mathrm{N}, 125^{\circ} 08^{\prime} \mathrm{W}\right)$, during the summer of 1991. Lacuna variegata and $L$. vincta were collected in the intertidal zone in Bamfield Inlet and Trevor Channel, Barkley Sound [the genus Lacuna is taxonomically complex and its nomenclature needs to be revised (D. Padilla pers. comm.); in the present study, juveniles of $L$. vincta may include those of a very similar species, L. porrecta].

Flow tank and water current generator. A miniature flow tank and water current generator were constructed (Fig. 1). The flow tank allowed laboratory observation of footraising and drifting behaviours of small Lacuna spp. under unidirectional and oscillatory water current conditions. The tank consisted of a
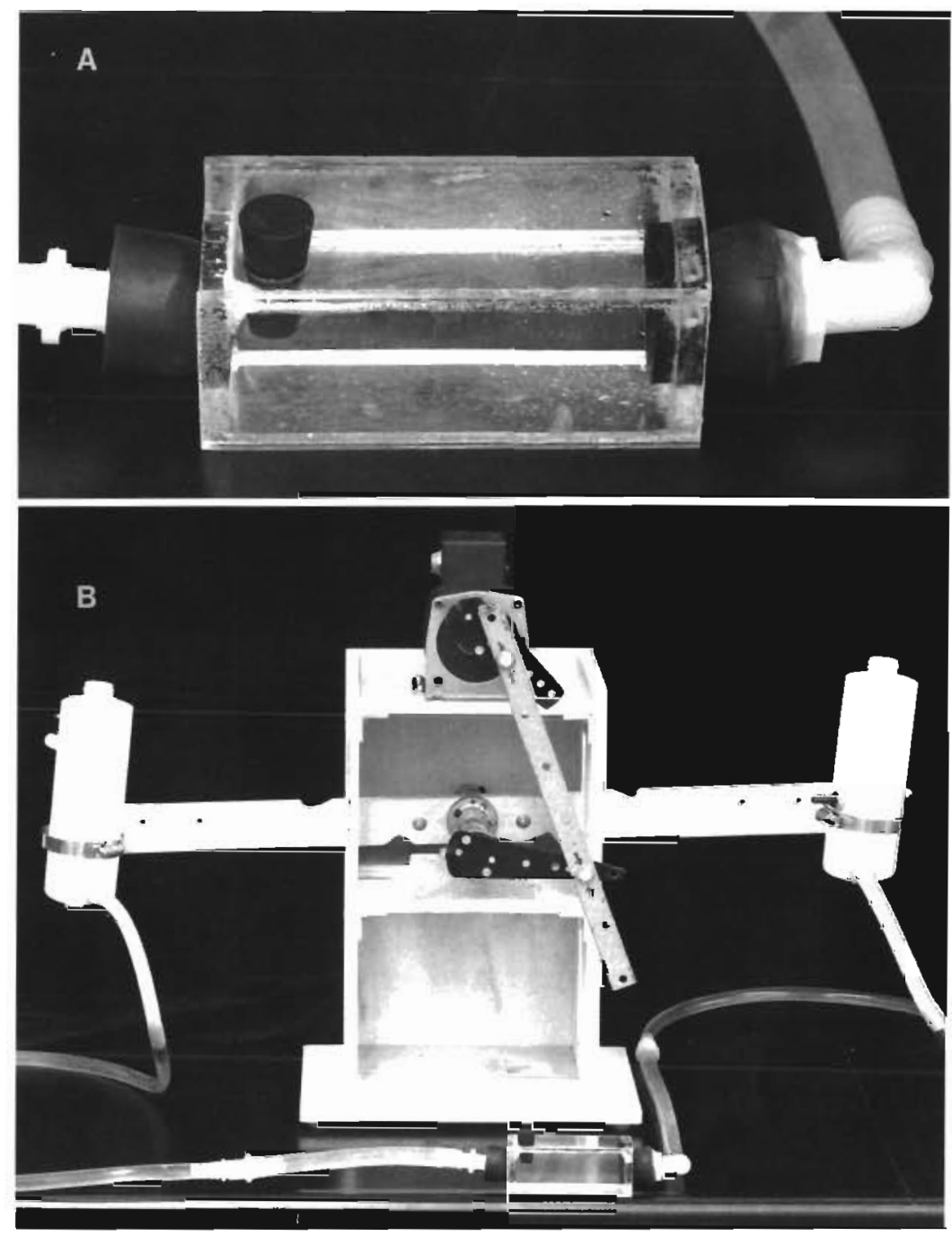

Fig. 1. (A) The microflow tank and (B) water current generator used to study the drifting behaviour of Lacuna spp. The tank is $10.4 \mathrm{~cm}$ long $\times 4.8 \mathrm{~cm}$ wide $\times$ $4.1 \mathrm{~cm}$ deep. The rubber plug (top left) allowed placing snails inside the tank as well as releasing the air when filling the system with seawater. The $90 \mathrm{~V} \mathrm{DC}$ electric motor, swinging support arm (72 cm long), $500 \mathrm{ml}$ water bottles and connecting hoses are visible in (B); note the small size of the flow tank (bottom) rectangular acrylic chamber $10.4 \mathrm{~cm}$ long $\times 4.8 \mathrm{~cm}$ wide $\times 4.1 \mathrm{~cm}$ deep (Fig. 1A). A hole $25 \mathrm{~mm}$ in diameter was drilled at each end of the chamber to connect 2 hoses so that seawater could flow through the tank, thus generating an artificial current. An additional hole $10 \mathrm{~mm}$ in diameter was drilled on the top left corner of the tank (Fig. 1A). This hole, normally closed by a rubber plug during experimentation, allowed air to escape when filling hoses and the tank with seawater; it was also used for placing snails inside the flow chamber. The tank was placed under an Olympus SZH stereomicroscope equipped with a Javelin video camera (model JE3462RGB). Behaviour sequences were recorded using a S-VHS Sony recorder (model SLV R5UC).

The water current generator consisted of a gravityfed system made of two $500 \mathrm{ml}$ plastic bottles, clamped in a vertical position at each end of a $72 \mathrm{~cm}$ wooden swinging support arm (Fig. 1B). The arm with the 2 clamped bottles was pivoted up and down alternatively by a $90 \mathrm{~V}$ DC electric motor (Bison Co., Model no. 011-105-8362; maximum RPM: 5). Two plastic hoses of $12 \mathrm{~mm}$ (inside diameter) were connected to the bottom of each bottle, and to each end of the flow tank (Fig. 1A, B). Peak water velocity during each cycle of the oscillatory water flow in the tank was adjusted by: (1) varying the elevation between the 2 bottles along the support arm; or (2) adjusting the push rod system connecting the electric motor to the 
support arm (Fig. 1B). A variable voltage transformer allowed adjustment of the speed of the motor and thus the pivot frequency of the support arm - set at 8 to $9 \mathrm{~s}$ cycle ${ }^{-1}$; this period of flow oscillation is comparable to that of incoming waves in the intertidal, i.e. on the order of 10 s; see Denny (1988). Fluoresceine (dye) was used to calculate water velocity in the central portion of the chamber. The peak water velocity was set at 15 to $17 \mathrm{~cm} \mathrm{~s}^{-1}$, which is likely significantly lower than that sometimes experienced by the snails in the field (see Denny 1988). A flow-through system, consisting of an input and of an overflow hose connecting each bottle on the support arm to the seawater system was used to maintain a continuous flow of seawater (temperature $=11$ to $12^{\circ} \mathrm{C}$ ) (Fig. 1B).

Effect of body size. For both species of Lacuna, various size classes were tested to study the effect of body size on foot-raising behaviour and initiation of postmetamorphic drifting. Snails used for this experiment were initially kept for $24 \mathrm{~h}$ in clean (no algae) plastic petri dishes with $600 \mu \mathrm{m}$ mesh windows to allow water circulation. For each trial, an individual snail was placed in the centre of the flow tank. The snail was left crawling inside the tank for 5 to $10 \mathrm{~s}$ before turning on the oscillatory current generator. The behaviour of the snail was recorded for $1 \mathrm{~min}$ and each individual was tested only once. Snails which did not raise the foot after 1 min but continued to crawl were considered unresponsive. This $1 \mathrm{~min}$ criterion was reasonable because most snails responded within 2 to $15 \mathrm{~s}$ of current initiation.

Effect of water current. Snails were observed in both still water and water current situations to determine whether water flow triggers foot-raising and drifting behaviours in Lacuna spp. In the still water situation (control), the 2 water bottles attached to the support arm were at the same level during the observation, thus preventing any water flow in the tank. In the water current situation (treatment), both oscillatory and unidirectional water flows were tested. The oscillatory flow was created by adjusting the water current generator to 8 to $9 \mathrm{~s} \mathrm{cycle}^{-1}$, with peak velocity during each cycle set at 15 to $17 \mathrm{~cm} \mathrm{~s}^{-1}$. To obtain a unidirectional current, a difference in elevation between the 2 bottles was maintained by keeping the support arm in a fixed position (electric motor turned off); this elevation was adjusted so that water velocity in the tank would be approximately the same as that during the peak of the oscillatory current (i.e. 15 to $17 \mathrm{~cm} \mathrm{~s}^{-1}$ ).

Effect of microhabitat. The effect of microhabitat on the drifting behaviour of Lacuna spp. was studied by comparing the behaviour of snails that had been maintained in 2 different types of microhabitats for $24 \mathrm{~h}$ before being positioned in the flow tank and exposed to an oscillatory water current. The 2 microhabitats were classified as: (1) favourable: dishes containing some of the algal species from which individual snails were originally collected (Ulva lactuca and Odonthalia floccosa), and (2) unfavourable: clean dishes.

The $G$-test of independence $[2 \times N$ contingency tables, $G$-statistic (Williams' correction used)], as described in Sokal \& Rohlf (1981) and using the BIOM statistical package, was used to test the effect of a given factor on the behaviour of snails.

\section{RESULTS}

\section{Effect of body size}

Body size had a marked effect on the triggering of foot-raising behaviour as well as on the initiation of mucous-thread drifting in Lacuna vincta (foot-raising: $G=36.62, \mathrm{p}<0.001$; drifting: $G=34.87, \mathrm{p}<0.001$ ) (Fig. 2A). Although adults (ca $\geq 3.5$ to $4 \mathrm{~mm}$ shell length) did display foot-raising behaviour and were capable of initiating drifting when exposed to oscillatory water current, juvenile stages (ca $\leq 3 \mathrm{~mm}$ ) were more responsive than larger individuals (Fig. 2A). In contrast, no evidence of size effect was detected in $L$. variegata (size range used: 1 to $5 \mathrm{~mm}$ ); adults (ca $\geq 2.5$ to $3 \mathrm{~mm}$ ) displayed foot-raising behaviour and initiated drifting as frequently as juveniles when exposed to oscillatory water currents (foot-raising: $G=1.59, \mathrm{p}>$ 0.05; drifting: $G=6.57, \mathrm{p}>0.05$ ) (Fig. 2A).

\section{Effect of current}

Experiments in which snails ( 1.1 to $2.4 \mathrm{~mm}$ ) were put in the flow tank and exposed to current or still water revealed that water current was responsible for the triggering of foot-raising and initiation of mucous-thread drifting behaviours in both Lacuna variegata (footraising: $G=33.2, \mathrm{p}<0.001$; drifting: $G=41.27, \mathrm{p}<0.001$ ) and $L$. vincta (foot-raising and drifting: $G=19.1, \mathrm{p}<$ 0.001 ) (Fig. 2B). One individual displayed foot-raising in the absence of water current, but it was incapable of initiating mucous-thread drifting (Fig. 2B).

The frequency of foot-raising and drifting behaviours between unidirectional and oscillatory currents did not differ significantly (Lacuna variegata, $G=0.52$, $\mathrm{p}>0.05 ;$ L. vincta: $G=0.06, \mathrm{p}>0.05)$ (Fig 2B).

\section{Effect of microhabitat}

The type of microhabitat to which individual Lacuna spp. were exposed prior to being placed in the flow tank had a marked effect on the frequency of foot- 


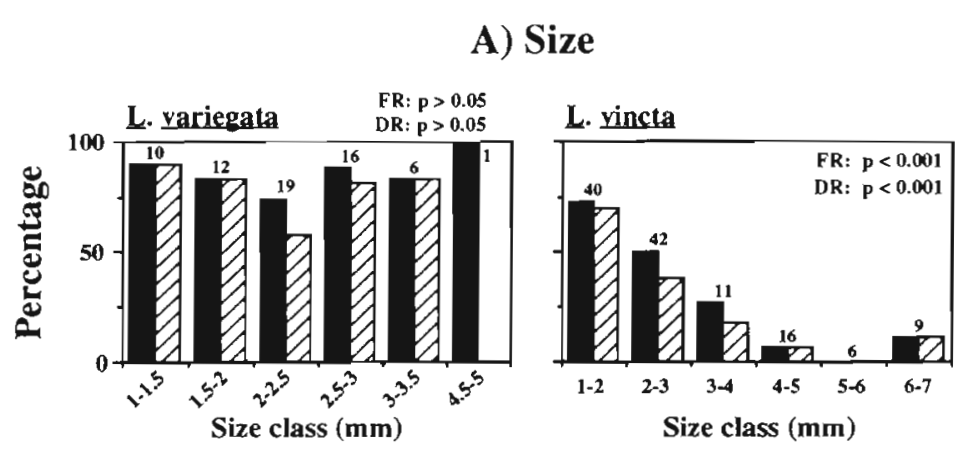

B) Current

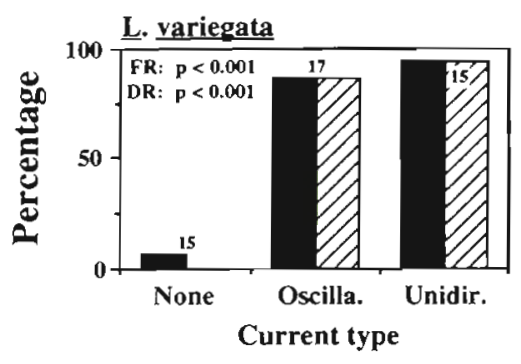

L. vincta

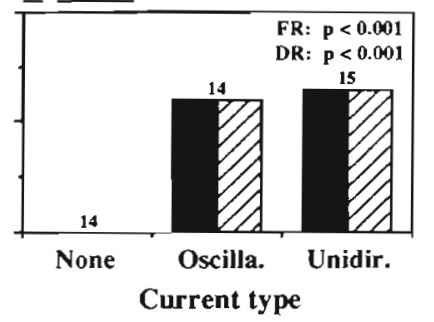

C) Microhabitat

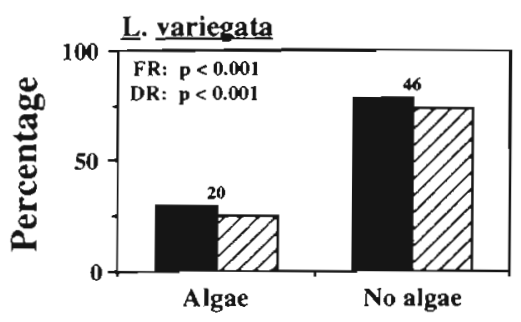

Microhabitat

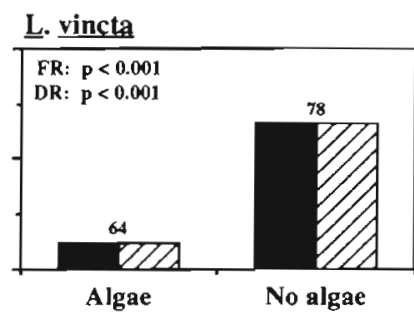

Microhabitat

Foot-raising (FR)

Drifting (DR)

Fig. 2. Effects of (A) body size, (B) water current and (C) microhabitat on the percentage of individual Lacuna variegata and $L$. vincta displaying foot-raising and mucous-thread drifting behaviours in the microflow tank. Size range of snails used for the water current and microhabitat experiments: 1.1 to $2.4 \mathrm{~mm}$ shell length. Value above bars indicates no. of snails per expt

raising and drifting behaviours in response to oscillatory flows (Fig. 2C). In both species, juveniles (size range used: 1.1 to $2.4 \mathrm{~mm}$ shell length) maintained in unfavourable microhabitats for $24 \mathrm{~h}$ before the experiment (clean dishes), showed foot-raising behaviour and initiated mucous-thread drifting 3 to 5 times more often than individuals maintained in dishes containing algae before the experiment ( $L$. variegata, foot-raising: $G=13.49, \mathrm{p}<0.001 ;$ drifting: $G=13.6, \mathrm{p}<0.001 ; L$. vincta, foot-raising and drifting: $G=45.4, \mathrm{p}<0.001)$ (Fig. 2C).

Juvenile Lacuna vincta (1.2 to $1.7 \mathrm{~mm}$ ) kept for $24 \mathrm{~h}$ in dishes containing no algae before the experiment also produced significantly less fecal pellets than individuals kept in dishes containing algae for the same period (algal microhabitat: mean $=22.65$ pellets $24 \mathrm{~h}^{-1} ;$ median $=20$; range $=4$ to 52 ; clean microhabitat: mean $=$ 14.56 pellets $24 \mathrm{~h}^{-1} ;$ median $=14.5$; range 6 to 29; Mann-Whitney test, $\mathrm{p}<0.05)$. Juveniles maintained in clean dishes were not feeding while those maintained in dishes containing algae were feeding. The occurrence of feeding in individuals maintained in dishes containing algae was also confirmed by the presence of grazed patches visible on the plants.

\section{DISCUSSION}

Body size, water current and microhabitat affect the initiation of foot-raising and mucous-thread drifting behaviours in Lacuna spp. Laboratory experiments indicate that although adult $L$. vincta raised their foot and initiated drifting when exposed to water currents, juveniles displayed these 2 behaviours much more frequently than adults (Fig. 2A). Martel \& Chia (1991b) demonstrated the superior ability of juvenile (mostly individuals $\leq 2.5 \mathrm{~mm}$ ) Lacuna spp. to drift in the water column compared with large individuals. During mucous-thread drifting small individuals had lower sinking rates (in a still water column) compared to adults (Martel \& Chia 1991b).

The size effect observed in Lacuna vincta contrasted with results obtained with $L$. variegata, where no evidence of size effect was detected. Whether stronger currents than those used in the present study would have been necessary to increase the frequency of the triggering of foot-raising behaviour of larger $L$. vincta in the flow tank is unknown. A study on post-metamorphic drifters using off-bottom algal collectors left overnight in Barkley Sound revealed that large $L$. vincta were trapped in much fewer numbers than $L$. variegata, with all individuals with shell length $\geq 4 \mathrm{~mm}$ belonging to the latter species (Martel 1990). The drifting behaviour of adult stages may differ between the 2 species.

Both unidirectional and oscillatory water flows trigger the foot-raising and mucous-thread drifting behaviours in Lacuna variegata and $L$. vincta. These results corroborate findings where Lacuna spp. were collected in large numbers in off-bottom collectors deployed in both a semi-exposed rocky intertidal area - highly turbulent, with mostly oscillatory flow - and in a protected 
subtidal inlet near Macrocystis integrifolia beds, where water currents were typically unidirectional, changing only with the tide (Martel 1990, Martel \& Chia 1991c).

Snails exposed to water currents demonstrated active participation in the initiation of mucous-drifting Alternatively, it may be said that these individuals were dislodged by the increased hydrodynamic pressure exerted on their shell and foot. However, 2 observations disprove this hypothesis. Firstly, foot-raising behaviour was occasionally observed when water current was as low as 1 to $2 \mathrm{~cm} \mathrm{~s}^{-1}$ and sometimes with no water current at all. This indicates that water current was not responsible for the lifting of the metapodium of the foot in a vertical position; foot-raising is rather a distinct behavioural response from the snail, which precedes voluntary mucous-drifting (although mucous-drifting also occurred in snails accidentally dislodged) (Martel \& Chia 1991b). Secondly, individual Lacuna spp. were exposed to low velocity currents only. Laboratory observations also indicated that snails gradually exposed to currents as high as 50 to $70 \mathrm{~cm}$ $\mathrm{s}^{-1}$ were not dislodged (Martel unpubl.). Martel \& Chia (1991b) showed the foot-raising response is clearly a distinct behavioural response involving strong contractions of the muscle fibres of the foot and the lifting of the metapodium, a behaviour which normally leads to mucous-thread drifting when the snail is exposed to water currents. Hence, these observations support the theory that in L. variegata and L. vincta, foot-raising behaviour is not the simple result of physical dislodgement by water currents; on the contrary, observations indicate that these snails can control the initiation of dispersal. Laboratory observations also suggest that the release process from the substrate is mediated by contraction of the propodium (Martel \& Diefenbach pers. obs.). The functional significance of the brief delay between foot-raising and actual release from the substrate (initiation of drifting) (a delay lasting usually less than $2 \mathrm{~s}$ in the present study) could be to allow a mucous thread of sufficient length to extend and thus to increase the hydrodynamic drag prior to release.

The ability of post-metamorphic Lacuna spp. to initiate mucous-thread drifting to escape from unfavourable microhabitats, such as those lacking proper algal substrate or shelter, may have adaptive benefits. Firstly, because the type of algae used by these gastropods has a marked effect on growth and fecundity of individuals (Martel 1990), relocation to a better algal substrate may increase growth rates as well as reproductive fitness. Studies in a rocky intertidal seaweed community suggest post-metamorphic drifting enables juvenile Lacuna spp. to relocate to microhabitats (algae) preferred by adults. This relocation followed episodes of larval settlement on seaweed species heavily used by veligers but not by adults (Martel 1990).
Similar migrations of juveniles to adult habitats occur in Mytilus edulis (Bayne 1964) and Macoma balthica (Beukema \& Vlas 1989). In Lacuna spp. this relocation to other algae by juveniles is facilitated since the mucous thread greatly enhances the snail's ability to attach to algae while drifting in the water column [Martel \& Chia (1991b); see also study by Blok \& TanMaas (1977) on function of byssal thread in Mytilus]. A second possible adaptive benefit of the ability of initiating drifting when in unfavourable microhabitats that lack shelter, is that escape, via mucous-thread drifting, may reduce risk of predation by mollusc-eating fishes such as embiotocids (seaperch), which prey on Lacuna spp. (Martel 1990)

Acknowledgements. We are most grateful to F. S. Chia and J. 1. Goldberg (University of Alberta) for logistical support during this study. A. Fogo, J. Fournier and A. Mathieu provided critical reading and helpful suggestions on earlier drafts of the manuscript. W. Bokman took the photographs. Special thanks to K. Klein and J. Topping for their assistance during the study as well as for their valuable comments and suggestions. We are also grateful to the Director and staff of the Bamfield Marine Station for their assistance and help during this study. This research was supported by a Canadian Museum of Nature RAC grant to A.M.

\section{LITERATURE CITED}

Bayne, B. L. (1964). Primary and secondary settlement in Mytilus edulis L. (Mollusca). J. Anim. Ecol. 33: 513-523

Beukema, J. J., Vlas, J de (1989). Tidal-current transport of thread-drifting postlarval juveniles of the bivalve Macoma balthica from the Wadden Sea to the North Sea. Mar. Ecol. Prog. Ser. 52: 193-200

Blok, J. W. de, Tan-Maas, M. (1977). Function of byssus threads in young postlarval Mytilus. Nature 267 $386-387$

Denny, M. W. (1988). Biology and the mechanics of the wave-swept environment. Princeton University Press, Princeton, NJ

Johnson, C. R., Mann, K. H. (1986). The importance of plant defence abilities to the structure of subtidal seaweed communities: the kelp Laminaria longicruris de la Pylaie survives grazing by the snail Lacuna vincta (Montagu) at high population densities. J. exp. mar. Biol. Ecol. 97 : $231-267$

Lane, D. J. W., Beaumont, A. R., Hunter, J. R. (1985). Byssus drifting and the drifting threads of the young post-larval mussel Mytilus edulis. Mar. Biol. 84: 301-308

Lane, D. J. W., Nott, J. A., Crisp, D. J. (1982). Enlarged stem glands in the foot of the post-larval mussel, Mytilus edulis: adaptation for bysso-pelagic migration. J. mar. biol. Ass U.K. 62: 809-818

Martel, A. (1990). Recruitment, post-metamorphic drifting and reproductive ecology in the herbivorous gastropod Lacuna spp. within kelp canopies and intertidal seaweed communities. Ph.D. dissertation, University of Alberta, Edmonton

Martel, A. (1993). Dispersal and recruitment of zebra mussels (Dreissena polymorpha) in a near-shore area in westcentral Lake Erie: the significance of post-metamorphic drifting. Can. J. Fish. Aquat, Sci, 50: 3-12 
Martel, A., Chia, F. S. (1991a). Drifting and dispersal of small bivalves and gastropods with direct development. J. exp mar. Biol. Ecol. 150: 131-147

Martel, A., Chia, F. S. (1991b). Foot-raising behaviour and active participation during the initial phase of post-metamorphic drifting in the gastropod Lacuna spp. Mar. Ecol. Prog. Ser. 72: 247-254

Martel, A., Chia, F. S. (1991c). Oviposition, Iarval abundance, in situ larval growth and recruitment of the herbivorous gastropod Lacuna spp. in kelp canopies in Barkley Sound, Vancouver Island. Mar. Biol. 110: 237-247

Prezant, R. S., Chalermwat, K. (1984). Floatation of the

This article was presented by J. M. Lawrence, Tampa Florida, USA bivalve Corbicula fluminea as a means of dispersal Science 225: 1491-1493

Sigurdsson, J. B., Titman, C. W., Davies, P. A. (1976). The dispersal of young post-larval bivalve molluscs by byssus threads. Nature 262: 386-387

Sokal, R. R., Rohlf, F. J. (1981). Biometry, 2nd edn. W. H. Freeman and Co., San Francisco, CA

Sorlin, $T$ (1988). Floating behaviour in the tellinid bivalve Macoma balthica (L.). Oecologia 77: 273-277

Vahl, O. (1983). Mucus drifting in the limpet Helcion (=Patina) pellucidus (Prosobranchia, Patellidae). Sarsia 68: $209-211$

Manuscript first received: December 10, 1992

Revised version accepted. June 14, 1993 